\title{
Expression of infection-related genes in parasites and host during murine experimental infection with Leishmania (Leishmania) amazonensis
}

\author{
Bernardo Acácio Santini Pereira, Constança Britto, Carlos Roberto Alves*

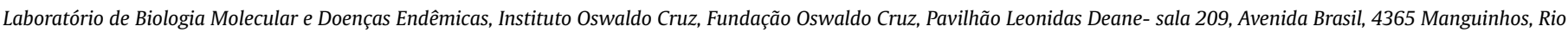 \\ de Janeiro/RJ, CEP 21040-360, Brasil
}

\section{A R T I C L E I N F O}

\section{Article history:}

Received 18 August 2011

Received in revised form

9 November 2011

Accepted 30 November 2011

Available online 7 December 2011

\section{Keywords:}

Leishmania spp

Animal model

Gene expression

Rodent

MHC

Protease

\begin{abstract}
A B S T R A C T
Leishmania parasites are able to interfere with host immune responses on many levels, as $\mathrm{T}$ cell responses balance, as observed in the murine model of infection. In the present study, we analyzed genes expression in both host and parasite during the progression of infection. Host genes associated to Tlymphocytes responses, MHC classes I and II, as well as parasite enzymes genes, cysteine-proteinases(CP) $\mathrm{B}$ and $\mathrm{C}$, were examined in mice along evolution of infection by Leishmania (Leishmania) amazonensis. Murine strains with distinct levels of susceptibility to infection presented different patterns of MHC genes expression: MHC class I genes tend to have higher expression levels in CBA mice, whereas MHC class II genes expression predominates in BALB/c mice. CPB genes expression in the parasites was shown to predominate over CPC in both mice strains tested. Understanding genes expression patterns during infection may lead to new and more efficient treatments for leishmaniasis.
\end{abstract}

Crown Copyright @ 2011 Published by Elsevier Ltd. All rights reserved.

\section{Introduction}

Despite its worldwide relevance, with a prevalence of 12 million patients and an estimated incidence rate of 2 million new cases per year [1], leishmaniasis has remained a neglected tropical disease [2]. Currently, the importance of this disease is growing, as it has been expanding its geographical distribution since the beginning of the 1990s [3,4].

Thus, information regarding the many aspects of Leishmania infections, such as virulence factors, parasite life cycles or host-parasite interactions, is necessary as it may lead to the development of new chemotherapies or strategies for the control of disease transmission.

Leishmaniasis may present many distinct clinical features but, in general, is classified into one of four groups: localized cutaneous, diffuse cutaneous, mucosal or visceral. Even within these groups the aspects of the infection may be different, depending on the species of the parasite causing the infection [4].

An important characteristic of Leishmania infection is the ability of these parasites to control their hosts' immune responses on

\footnotetext{
* Corresponding author. Tel.: +55 213865 8191; fax: +55 2125903495.

E-mail addresses: bpereira@ioc.fiocruz.br (B.A.S. Pereira), cbritto@ioc.fiocruz.br (C. Britto), calves@ioc.fiocruz.br (C.R. Alves).
}

many levels. In the murine model of experimental infection with Leishmania (Leishmania) major, an aspect of the immune system that is of pivotal importance in the establishment of infection is the T helper cell [types 1 (Th1) and 2 (Th2)] response.

It has been reported that in susceptible murine strains, such as the BALB/c strain, a Th2 response is elicited and is associated with disease exacerbation, whereas in resistant strains, such as the C57BL/6 strain, a Th1 response restrains the infection [5]. In addition, a cytotoxic T cell (Tc) response has been shown to correlate with infection control in mice [6].

Despite the fact that the roles of Th responses are not as welldefined in murine infections by species from the Leishmania (Leishmania) mexicana complex, many mechanisms have been reported in these species that either induce a Th2 response or inhibit a Th1 response, revealing the fine level of control that the parasites have over their hosts immune system, as reviewed for Leishmania (Leishmania) amazonensis by Pereira \& Alves [7].

For example, a cysteine-proteinase (CP) from $L$. (L.) mexicana, designated cysteine-proteinase $\mathrm{B}(\mathrm{CPB})$, has been reported to modify the balance between the two Th responses, favoring a Th2 response [8]. L. (L.) mexicana mutants that lack CPB production were not able to induce interleukin (IL)-4 expression in infected $\mathrm{BALB} / \mathrm{c}$ mice and, thus, failed to stimulate a Th2 response and establish infection [9]. It was postulated that CPB may be involved in the degradation of the nuclear transcription factor $\kappa \mathrm{B}(\mathrm{NF} \kappa \mathrm{B})$, and 
also in the degradation of NFKB inhibitor subunits $\alpha$ and $\beta$, thereby inhibiting IL-12 production and a Th1 response [10].

CPB is a cathepsin-L-like CP (Clan CA, Family C1) that presents a $\mathrm{COOH}$-terminal extension of approximately 100 amino acids, which is cleaved when the enzyme achieves its mature form. Also, CPB has multiple isoforms, which are coded by genes organized in a tandem array. CPC is a cathepsin-B-like CP coded by a single copy gene and does not present a $\mathrm{COOH}$-terminal extension [8].

The COOH-terminal extension of CPB may play a role in the regulation of the host Th responses by the parasite. Our group previously published a report defining peptides derived from the $\mathrm{COOH}$-terminal of $\mathrm{CPB}$ with features that suggest that they may act as epitopes for murine major histocompatibility complex (MHC) class I molecules. One of these peptides (PI) was able to affect the production of cytokines and to influence the percentages of CD4+ and CD8 + cells in cultures obtained from the lymph nodes of mice infected with $L$. (L.) amazonensis. The peptide PI induced the expression of Th2 response-related cyokines in cells from a susceptible strain (BALB/c) and cytokines related to both Th1/Th2 responses in cells from a moderately resistant strain (CBA) [11].

Despite the importance of CPs, such as CPB (and possibly others, including $\mathrm{CPA}$ and $\mathrm{CPC}$ ), in influencing the outcomes of infections by species of the $L$. (L.) mexicana complex, no data is yet available regarding the levels of $\mathrm{CPB}$ genes expression during infections.

Similarly, the levels of hosts MHC class I and II genes expression have not been studied during the evolution of the infection. MHC class I molecules are generally related to a cytotoxic CD8+ lymphocytes response, whereas MHC class II molecules relate to a helper CD4+ lymphocytes response and thus, play a major role in the outcome of the infection. The analysis of the mRNA expression levels of these factors can contribute in the comprehension of the organization dynamics of the host immune response during the infection.

Therefore, in the present study, we propose a strategy to assess gene expression levels for $L$. (L.) amazonensis infection-related enzymes (CPB and CPC) and for hosts MHC class I and MHC class II molecules (in BALB/c and CBA mouse strains) using real-time polymerase chain reaction (PCR) assays. We have opted to use these two murine strains, because there is no inbred murine strain which is completely resistant to $L$. (L.) amazonensis but the level of susceptibility varies among the strains [7], and, thus, we wanted to assess if these variations in susceptibility would be associated to differences regarding gene expression, either in the host itself or the parasites infecting it.

\section{Materials and methods}

\subsection{Cultivation of parasites}

L. (L.) amazonensis MHOM/BR/1977/LTB0016 strain promastigotes, obtained from Oswaldo Cruz Institute Leishmania collection (Coleção de Leishmania do Instituto Oswaldo Cruz CLIOC/IOC Fiocruz), were grown in Schneider medium (Sigma-Aldrich Inc., USA) supplemented with $10 \%$ fetal calf serum for 4 days at $28{ }^{\circ} \mathrm{C}$. For use in experimental infections, parasites were washed three times with $50 \mathrm{mM}$ phosphate buffered saline (PBS) ( $\mathrm{pH} \mathrm{7.2)}$ centrifuged $\left(2000 \times \mathrm{g}, 10 \mathrm{~min}, 4^{\circ} \mathrm{C}\right)$, counted using a Neubauer chamber and suspended in PBS at a concentration of $2 \times 10^{7}$ cells/ $\mathrm{mL}$.

\subsection{Experimental murine infection}

Female specific pathogen-free (SPF) mice with 5-7 weeks (strains $\mathrm{BALB} / \mathrm{c}$ and $\mathrm{CBA}$ ) were obtained from the animal care facility of Fiocruz (Centro de Criação de Animais de Laboratório CECAL/Fiocruz). Each animal was inoculated subcutaneously with
$1 \times 106$ promastigotes in PBS $(50 \mu \mathrm{L})$ at its posterior left hindpaw. Lesion development was monitored using a pachymeter in three random animals of each strain. Hindpaw width and height were used to estimate lesion area $\left(\mathrm{mm}^{2}\right)$. Every two weeks, two animals were euthanized in $\mathrm{CO}_{2}$ chambers and samples from the inoculation site (hindpawn) and its draining lymph node were collected, homogenized in Trizol reagent (Invitrogen, Life Technologies, USA) and stored at $-70^{\circ} \mathrm{C}$. All procedures using animals were approved by the Animal Ethics Committee of Fiocruz (Comissão de Ética no Uso de Animais - CEUA/Fiocruz; L-0006/07).

\subsection{Total RNA extraction}

Total RNA from mouse hindpaw lesion and lymph node samples was extracted using Trizol, according to manufacturer's instructions. Briefly, insoluble materials were removed by centrifugation $\left(12,000 \times \mathrm{g}, 10 \mathrm{~min}, 4{ }^{\circ} \mathrm{C}\right)$ and supernatants were mixed with chloroform (proportion 1:5, $3 \mathrm{~min}, 25^{\circ} \mathrm{C}$ ), following centrifugation $\left(12,000 \times \mathrm{g}, 15 \mathrm{~min}, 4^{\circ} \mathrm{C}\right)$, to enable phase separation. The mixture aqueous phase was reserved, mixed with isopropyl alcohol (proportion 1:1, $10 \mathrm{~min}$ at room temperature) and centrifuged $\left(12,000 \times \mathrm{g}, 10 \mathrm{~min}, 4^{\circ} \mathrm{C}\right)$, to precipitate RNA pellets. RNA pellets were washed with $75 \%$ ethanol $\left(7500 \times \mathrm{g}, 5 \mathrm{~min}, 4^{\circ} \mathrm{C}\right)$, air-dried (10 min) and suspended in $50 \mu \mathrm{L}$ of DEPC-treated water (10 min, $60^{\circ} \mathrm{C}$ ). RNA samples were treated with DNAse I amplification grade (Invitrogen), according to manufacturer's instructions, and immediately converted to cDNA for further use (as described below).

\subsection{Synthesis of CDNA from the total RNA samples}

First-strand cDNA synthesis from total RNA samples was performed using the SuperScript III first-strand synthesis system for reverse transcriptase (RT)-PCR (Invitrogen), according to manufacturer's instructions. Briefly, $20 \mu \mathrm{L}$ of RT mix (containing $2.5 \mathrm{ng} / \mu \mathrm{L}$ of random hexamer primers, $0.5 \mathrm{mM}$ dNTPs, $1 \mathrm{x}$ RT buffer, $5 \mathrm{mM}$ $\mathrm{MgCl}_{2}, 0.01 \mathrm{M}$ DTT, $40 \mathrm{U}$ of RNaseOUT, $200 \mathrm{U}$ of SuperScript III RT and $8 \mu \mathrm{L}$ of RNA sample) were incubated as follows: $25{ }^{\circ} \mathrm{C}$ for $10 \mathrm{~min}, 50^{\circ} \mathrm{C}$ for $50 \mathrm{~min}, 85^{\circ} \mathrm{C}$ for $5 \mathrm{~min}$ and chilled on ice. Finally, 2 $\mathrm{U}$ of RNase $\mathrm{H}$ were added, incubated for $20 \mathrm{~min}$ at $37{ }^{\circ} \mathrm{C}$ and the samples were stored at $-20^{\circ} \mathrm{C}$ until further use.

\subsection{Selection of nucleotide sequences of interest used in primer design}

Housekeeping genes for normalization of real-time PCR expression results were elected based on available literature: $\alpha$ tubulin for Leishmania samples [12] and $\beta$-actin for mouse samples [13]. Leishmania $\alpha$-tubulin primers were designed using a consensus sequence present in $\alpha$-tubulin mRNA sequences from several Leishmania species (GenBank: XM_001563114.1, XM_001563113.1, XM_001566562.1, AY702009.1, XM_001464016.1 and XM_001681731). Murine $\beta$-actin primers were selected using as base a region of divergence between Mus musculus $\beta$-actin mRNA sequence (Genbank BC138614.1) and Homo sapiens sapiens $\beta$-actin mRNA sequence (Genbank NM_001101.3), to ensure no misleading results in the PCR assays due human contamination of samples.

Also, primers were selected for the analysis of Leishmania CPB (L-cathepsin-like CP) and CPC (B-cathepsin-like CP) expression. To design CPB primers, a consensus sequence from four $L$. (L.) mexicana CPB sequences (GenBank AJ319727.1, Z49963.2, Z49962.2 and Y09958.1) and one L. (L.) mexicana CPB mRNA sequence (GenBank M97695.1) were used. CPC primers were designed using the $L$. (L.) mexicana CPC gene sequence (GenBank Z48599.1).

Additionally, primers were designed to assess the expression of murine MHC class I and II genes. To select such primers, it was 
necessary to define consensus regions for murine MHC genes classes I and II. A consensus region from MHC class I genes was defined using sequences from two H-2 types: K (GenBank M18525.1 and M11975.1) and D (GenBank M18524.1 and L29190.1 and GeneID 14964). To define a consensus region for MHC class II, sequences from the $\alpha$-chain of $\mathrm{H}-2$ types $\mathrm{E}$ (GeneID 14968) and A (GeneID 14960) genes were used.

\subsection{Design of primers}

All primers used in this study were designed using Primer3 v. 0.4 .0 (http://frodo.wi.mit.edu/primer3/). Default settings were used, except for Product Size Ranges, which was set to 80-120 bp. Primers used were synthesized on a $50 \mathrm{nM}$ scale and purified by desalinization (Invitrogen)

\subsection{Conventional PCR assays}

Conventional PCR assays were performed using PCR mixtures (50 $\mu \mathrm{L}$ ) consisting of: $1 \mathrm{x}$ Taq Platinum PCR buffer (Invitrogen), $4 \mathrm{mM} \mathrm{MgCl} 2,0.2 \mathrm{mM}$ dNTPs (Invitrogen), $2 \mathrm{ng} / \mu \mathrm{L}$ of each primer, 1.25 U of Platinum Taq DNA Polymerase (Invitrogen) and DEPCtreated water up to $45 \mu \mathrm{L}$. A total of $5 \mu \mathrm{L}$ of each cDNA sample (diluted 1:50 in DEPC-treated water) was used in each reaction. Samples were run in duplicates. The PCR conditions were as follows: initial denaturation at $94{ }^{\circ} \mathrm{C}$ for $3 \mathrm{~min}$ ( 1 cycle); 40 cycles of denaturation at $95{ }^{\circ} \mathrm{C}$ for $20 \mathrm{~s}$, annealing at $56{ }^{\circ} \mathrm{C}$ for $30 \mathrm{~s}$ and extension at $72{ }^{\circ} \mathrm{C}$ for $30 \mathrm{~s}$; and a final extension at $72{ }^{\circ} \mathrm{C}$ for $5 \mathrm{~min}$. All PCR assays were performed using an Eppendorf Mastercycler thermal cycler (Eppendorf AG, German). PCR products were separated by electrophoresis in $2 \%$ agarose gels ( $100 \mathrm{~V}$ for $1.5 \mathrm{~h}$ ), visualized by ethidium bromide staining and photographed with an EasyDoc 100 photodocumentation system (Bioagency Biotecnologia, Brazil). The assays were run in triplicate.

\subsection{Sequencing of $P C R$ products and BLAST analysis}

PCR products were purified using Wizard SV Gels and the PCR Clean-Up System (Promega Corporation, USA), according to manufacturer's instructions. Briefly, gel slices containing PCR products were mixed with membrane binding solution (1:1), incubated in SV mini-columns (1 min, room temperature), washed twice with membrane washing solution (with ethanol), centrifuged $\left(10,000 \times \mathrm{g}, 5 \mathrm{~min}, 20^{\circ} \mathrm{C}\right)$ and suspended in DEPC-treated water $(50 \mu \mathrm{L})$ by centrifugation $\left(10,000 \times \mathrm{g}, 1 \mathrm{~min}, 20^{\circ} \mathrm{C}\right)$. Sequencing of PCR products was performed by the PDTIS/Fiocruz DNA sequencing platform, using a 3730 DNA Analyzer (Applied Biosystems, Life Technologies, USA). The sequences obtained were utilized as queries in the NCBI Basic Local Alignment Search Tool [BLAST] (http://blast.ncbi.nlm.nih.gov/Blast.cgi), using the following parameters: nucleotide BLAST and BLASTn algorithms. The databases used were 'mouse genomic + transcript' and 'Leishmania' (taxid numbers: 5658 and 38568).

\subsection{Real-time PCR assays}

Real-time PCR assays were carried out using a 7500 Fast RealTime PCR System and analyzed with SDS 7500 software v. 2.0 (Applied Biosystems). Real-time PCR mixtures $(12.5 \mu \mathrm{L})$ were comprised of 1x Power SYBR Green PCR Master Mix (Applied Biosystems), $0.1 \mu \mathrm{M}$ of each primer and DEPC-treated water up to $10 \mu \mathrm{L}$. A total of $2.5 \mu \mathrm{L}$ of each cDNA sample (diluted 1:50 in DEPCtreated water) was used for each real-time PCR reaction. Samples were tested in duplicates. Default thermal cycling conditions of the PCR system were used (including the option for a continuous melting curve cycle), except for the amplification stage, where the same settings used in the conventional PCR assays were applied. Fluorescence data were collected in each cycle at the extension step $\left(72{ }^{\circ} \mathrm{C}\right)$. The assays were run in triplicate. To determine the efficiency of PCR assays, 2-fold serial dilutions of cDNA samples were used, with the threshold cycle $(\mathrm{Ct})$ of each dilution being defined and plotted on a semi-log $(\log 10)$ graph for analysis. The slopes of accurate tendency lines $\left(r^{2} \geq 0.98\right)$ were used to determine the efficiency of the reactions $\left(E=-1+10^{(-1 / \text { slope })}\right)$. $E$ values were used to correct the $\mathrm{Ct}$ values for the assayed samples according to the efficiency data $\mathrm{Ct}_{E=100 \%}=\mathrm{Ct} \times[\log (1+\mathrm{E}) / \log 2]$.

\subsection{Determination of relative gene expression}

The comparative $\mathrm{Ct}$ method $(\Delta \Delta \mathrm{Ct})$ was used to determine the levels of expression for the genes of interest. The calibrator used for Leishmania genes analysis was promastigotes samples, while for murine genes, healthy mice samples were used (both CBA and BALB/c). Alpha-tubulin and $\beta$-actin genes were used as endogenous controls for Leishmania and murine gene expression, respectively. Relative quantity (RQ) values or normalized levels expression were obtained by the formula $2^{-\Delta \Delta \mathrm{Ct}}$.

\subsection{Statistical analysis}

To compare results from gene expression, two-tailed Student's $t$ test was applied, assuming equal variance between samples. For MHC genes expression, data matrices from subsequent weeks were compared, whereas for $\mathrm{CP}$ genes expression, data matrices for $\mathrm{CPB}$ and CPC from a same week were compared. Data matrices were considered statistically distinct when $p$-value was lower than 0.05 .

\section{Results}

\subsection{Selection of primers}

Using the consensus sequences defined above and the Primer3 tool, we were able to design primer pairs to specifically amplify regions that generated real-time PCR-compatible amplicons (Table 1).

\subsection{Standardization of $P C R$ conditions by conventional PCR}

To verify the specificity and functionality of the primers that were developed, and to define the most effective conditions for the PCR assays, a series of conventional PCR tests was performed. $L$. (L.) amazonensis promastigote cDNA samples were used as controls for

Table 1

Primer pairs designed for real-time PCR gene expression assays.

\begin{tabular}{|c|c|c|}
\hline $\begin{array}{l}\text { Sequence of } \\
\text { interest }\end{array}$ & Primers sequences & $\begin{array}{l}\text { Predicted } \\
\text { product } \\
\text { size (bp) }\end{array}$ \\
\hline Leishmania $\alpha$-tubulin & $\begin{array}{l}\text { Forward: 5'-TCAAGTGCGGCATCAACTAC-3' } \\
\text { Reverse: 5'-GAGTTGGCAATCATGCACAC-3' }\end{array}$ & 91 \\
\hline Leishmania СРВ & $\begin{array}{l}\text { Forward: 5'-AGGAGTTCAAGCGGACGTA-3' } \\
\text { Reverse: } 5^{\prime} \text {-CAGGTTGCGCTCGAAGTT-3' }\end{array}$ & 84 \\
\hline Leishmania СРC & $\begin{array}{l}\text { Forward: 5'-AAATGCAACACCACCTGTGA-3' } \\
\text { Reverse: 5'-TTCGCCCTTGATGGAGTAAG-3' }\end{array}$ & 81 \\
\hline Murine $\beta$-actin & $\begin{array}{l}\text { Forward: 5'-GTTTTGTTTTGGCGCTTTTG-3' } \\
\text { Reverse: 5'- AACTTTGGGGGATGTTTGCT-3' }\end{array}$ & 88 \\
\hline Murine MHC class I & $\begin{array}{l}\text { Forward: 5'-CGCTGAGGTATTTCGAGACC-3' } \\
\text { Reverse: 5'-AACTCCGTGTTGTCCACGTA-3' }\end{array}$ & 88 \\
\hline $\begin{array}{l}\text { Murine MHC } \\
\quad \text { class II ( } \alpha \text {-chain) }\end{array}$ & $\begin{array}{l}\text { Forward: 5'-GTGGATCACTGGGGCTTG-3' } \\
\text { Reverse: 5'-GACCCACAAACAACCCAAGA-3' }\end{array}$ & 115 \\
\hline
\end{tabular}


Leishmania primers and healthy BALB/c and CBA mice CDNA samples for murine primers. PCR settings were considered satisfactory when a single well-defined band was observed in a $2 \%$ agarose gel after electrophoresis of PCR products. Concomitantly, control assays were carried out pairing Leishmania primers with healthy mice samples and murine primers with $L$. (L.) amazonensis samples, to ensure primers specificity. No amplification was observed using these controls (data not shown). Under the conditions established, all amplicon sizes were identical to the predicted product sizes (Fig. 1). Subsequently, PCR products were sequenced and analyzed using BLAST, to check for primer specificity. The results showed that each amplicon was ranked as similar to a compatible sequence, indicating primers specificity (Table 2).

\subsection{Analysis of specificity and efficiency of real-time PCR assays}

Real-time PCR conditions were adapted from the protocol defined for conventional PCR using the same cDNA samples as controls. A single peak was observed in the melting curve of each reaction, indicating a unique product with a well-defined melting temperature (Table 2). Products from real-time PCR assays were also separated by electrophoresis in $2 \%$ agarose gels and sequenced. The results were identical to those previously obtained for conventional PCR products (data not shown).

The PCR amplification curve for each cDNA sample, a factor of key importance for a correct analysis of the relative expression data, was defined using 2 -fold serial dilutions (1:2-1:64) of $L$. (L.) amazonensis-infected mice hindpawn lesion samples (obtained 20 weeks post-infection for CBA and 16 weeks post-infection for BALB/ c) for Leishmania primers and healthy mice hindpawn samples (CBA and $B A L B / C$ ) for murine primers. The combination of primers pair and cDNA sample that presented the lowest efficiency was murine MHC class I primers with healthy CBA mice hindpawn sample with an efficiency of 58\%. The other combinations had efficiencies ranging from $78 \%$ to $112 \%$ (Table 3 ). All of these distinct efficiencies were considered when performing relative expression analysis and used for $\mathrm{Ct}$ values adjustment.

Also, beta actin mRNA levels presented no statistically significant differences among all samples tested (data not shown), indicating the usefulness of this target as a normalizer for gene expression analysis.

\subsection{Relative expression of MHC genes over the course of $L$. (L.) amazonensis murine infection}

To check for differences that could occur in the expression of MHC genes due to genotypic variability, cDNA samples from two strains of mice with distinct levels of susceptibility to $L$. (L.) amazonensis infection were tested: a medium susceptible strain, CBA

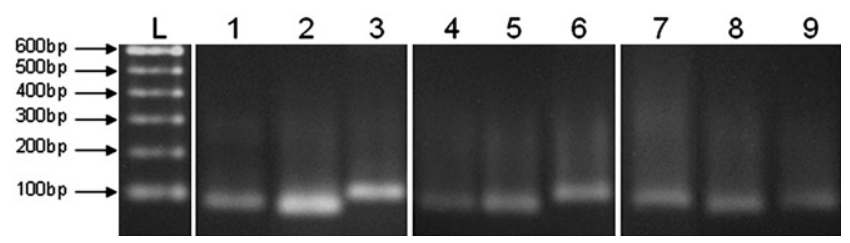

Fig. 1. Analysis of PCR products by electrophoresis in $2 \%$ agarose gels. (L) 100-bp DNA ladder (Invitrogen), used as molecular weight marker. (1-3) PCR products obtained using primers for murine $\beta$-actin, MHC class I and MHC class II ( $\alpha$-chain) genes, respectively, with CBA mice hindpawn samples. (4-6) PCR products obtained using primers for murine $\beta$-actin, MHC class I and MHC class II ( $\alpha$-chain) genes, respectively, with BALB/c mice hindpawn samples. (7-9) PCR products obtained using primers for Leishmania $\alpha$-tubulin, cysteine-proteinase B and cysteine-proteinase C, respectively, with $L$. (L.) amazonensis promastigote samples.
[14] and highly susceptible strain, BALB/c [15]. Samples were collected from two distinct sites, the hindpawn lesion and its draining lymph node, in succession throughout the infection: from the 2 nd to the 16 th week post-infection. Additional samples from the 18th and 20th weeks post-infection were collected for CBA mice, as they presented a slower lesion development than BALB/C mice (Fig. 2).

MHC class I RQ levels at the lesion site of CBA mice presented a peak at the 10th week of infection, followed by an abrupt decrease. MHC class II genes, at this same site, presented no statistically significant differences. RQ levels for MHC class I genes were consistently higher than those of MHC class II genes in lesion samples (Fig. 3A). In contrast, at the lesion-draining lymph node site of CBA mice, MHC class I and II RQ levels were much more similar. At this site, MHC class I presented an increase in the 6th week and a peak at the 8th week, whereas MHC class II reached a peak between the 4 th and 8 th week and then another at the 16 th week (Fig. 3B).

At the lesion site of BALB/c mice, MHC class I RQ levels started to increase around the 8th week post-infection, being undetectable prior to this week. As for MHC class II genes, RQ levels reached a peak at the 12th weeks, with a tendency to decrease further this time period. Contrary to the expression patterns observed in CBA mice, the RQ levels of MHC class II genes were, in general, higher than those of MHC class I (Fig. 3C).

At the draining lymph node site of BALB/c mice, MHC class II genes presented decreasing RQ levels in the first weeks, with an increase around the 12th week, whereas RQ levels of MHC class I genes were much lower throughout the course of infection. Once again, a general tendency of MHC class II RQ levels to be higher than those of MHC class I was observed (Fig. 3D).

An interesting feature is the fact that in both murine strains tested the expression levels for both MHC classes I and II genes were higher in samples obtained from the lesion site than from the draining lymph node.

\subsection{Predominance of $L$. (L.) amazonensis CPB gene expression over $C P C$ gene expression during the course of murine infection}

The RQ levels for $L$. (L.) amazonensis CPB and CPC genes were undetectable until the 8th week post-infection in the samples tested. Thus, a follow-up of gene expression study throughout the course of infection was not performed. However, RQ levels for CPB genes were much higher than those of CPC genes, in all samples tested, in any week of the infection course and in both CBA and $\mathrm{BALB} / \mathrm{c}$ mice, as shown in a set of representative samples from the 12th week post-infection (Fig. 4). It is also noteworthy that RQ levels of CPB genes, but not CPC genes, tended to be higher in BALB/ $c$ mice than in CBA mice.

\section{Discussion}

The murine model of Leishmania infection is a very interesting model for the application of gene expression analyses during disease development. Such model has been widely used for studies of many features of leishmaniasis, as it allows for a high level of control over characteristics that can influence the course of infection [7].

Due to its high sensitivity and specificity, the real-time PCR technique can be used to understand the expression patterns of genes associated to host-parasite interactions. These investigations can help to identify the roles that immune factors from the host and virulence factors from the parasite are playing in the evolution of the infection and, also, how the distinct stages of the disease are linked to patterns of gene expression. 
Table 2

NCBI BLAST results for Leishmania and murine PCR products.

\begin{tabular}{|c|c|c|c|}
\hline PCR product name & NCBI BLAST sequence name & BLAST expect value ${ }^{a}$ & BLAST score $(\text { bits })^{\mathrm{b}}$ \\
\hline Leishmania $\alpha$-tubulin & $\begin{array}{l}\text { Leishmania major alpha-tubulin (LmjF13.0390) mRNA } \\
\text { [GenID 5650068 LmjF13.0390] }\end{array}$ & $4 \times 10^{-13}$ & 73,4 \\
\hline Leishmania СРВ & $\begin{array}{l}\text { Leishmania mexicana mRNA for cysteine-proteinase } \\
\text { [GenBank Z14061.1] }\end{array}$ & $5 \times 10^{-15}$ & 84,2 \\
\hline Leishmania СРC & $\begin{array}{l}\text { L.mexicana lmcpc gene cathepsin-B-like cysteine-proteinase } \\
\text { [GenBank Z48599.1] }\end{array}$ & $1 \times 10^{-10}$ & 63,9 \\
\hline Murine $\beta$-actin [CBA] & $\begin{array}{l}\text { Mus musculus actin, beta cytoplasmic (Actb) mRNA } \\
\text { [Map Viewer NM_007393.2] }\end{array}$ & $2 \times 10^{-13}$ & 80,6 \\
\hline Murine MHC class I [CBA] & $\begin{array}{l}\text { PREDICTED: } \text { M. musculus similar to MHC class I histocompatibility } \\
\text { antigen H-2 Q4 alpha chain precursor - mouse (LOC436493) misc } \\
\text { RNA [GeneID } 436493 \mathrm{H} 2 \text {-gs } 10 \text { ] }\end{array}$ & $4 \times 10^{-05}$ & 53,6 \\
\hline Murine MHC class II ( $\alpha$-chain) [CBA] & $\begin{array}{l}\text { M. musculus histocompatibility 2, class II antigen E alpha (H2-Ea) } \\
\text { mRNA [Map Viewer NM_010381.2] }\end{array}$ & $1 \times 10^{-19}$ & 102 \\
\hline Murine $\beta$-actin $[\mathrm{BALB} / \mathrm{c}]$ & $\begin{array}{l}\text { M. musculus actin beta, cytoplasmic (Actb) mRNA } \\
\text { [Map Viewer NM_007393.2] }\end{array}$ & $3 \times 10^{-14}$ & 82,4 \\
\hline Murine MHC class I [BALB/c] & $\begin{array}{l}\text { PREDICTED: } \text { M. musculus MHC c6/g2 (Qa-2) protein (LOC634869) } \\
\text { mRNA [GeneID } 634869 \text { LOC634869] }\end{array}$ & $3 \times 10^{-07}$ & 59,0 \\
\hline Murine MHC class II ( $\alpha$-chain) $[\mathrm{BALB} / \mathrm{c}]$ & $\begin{array}{l}\text { M. musculus histocompatibility 2, class II antigen E alpha (H2-Ea) } \\
\text { mRNA [Map Viewer NM_010381.2] }\end{array}$ & $4 \times 10^{-13}$ & 82,4 \\
\hline
\end{tabular}

${ }^{a}$ BLAST expect value indicates the number of times the current match or a better one would occur in a search in the entire database by pure chance. A low expect value indicates a high significance for the match.

b BLAST score $\left(\mathrm{S}^{\prime}\right)$ is a normalized value derived from the raw alignment score $(\mathrm{S})$ by the following formula: $\mathrm{S}^{\prime}=(\lambda \mathrm{S}-\ln K) /(\ln 2)$, where $\mathrm{K}$ and $\lambda$ are the statistical parameters of the scoring system. It is useful to compare alignment scores from distinct searches.

In fact, a recent report shows that gene expression patterns analyzed by microarray in BALB/c mice macrophages infected in vitro with $L$. (L.) amazonensis are significantly distinct from those of uninfected macrophages [16]. In this case there is an upregulation of genes related to glycolysis, fatty acid biosynthesis and catabolism of triglycerides. On the other, genes related to extracellular lipolysis were down-regulated, as well as many genes related to immunity components: classical and alternate complement pathways, Toll-like receptors signaling pathway, chemokine receptors and histocompatibility molecules.

The capacity of $L$. (L.) amazonensis to influence host genes expression was also observed in vivo using experimentally infected C57BL/6 mice [17]. In that study, gene expression profiles were compared between mice infected with $L$. (L.) amazonensis and $L$. (L.) major. By applying RNAse protection analysis (RPA) in samples from lesion-draining lymph nodes, it was detected that $L$. (L.) amazonensis-infected mice expressed much lower mRNA levels of interferon (IFN) $\gamma$, interleukin (IL)-12, IL-4, IL- $1 \alpha$ and IL- $\beta$ that $L$. (L.) major-infected mice. These patterns remained for all the infection period analyzed (until the 8 th week post-infection). Similar results, however with more exacerbated differences, were observed for IL$1 \alpha$ and IL- $\beta$ mRNA levels in the lesion site. The analysis of chemokine expression [RANTES, macrophage inflammatory protein (MIP)- $1 \alpha$, MIP-1 $\beta$, MIP-2 and monocyte chemotactic protein (MCP)-1]

Table 3

Analysis of specificity and efficiency of real-time PCR assays.

\begin{tabular}{llc}
\hline PCR product & $\begin{array}{l}\text { Melting } \\
\text { temperature }\left({ }^{\circ} \mathrm{C}\right)^{\mathrm{a}}\end{array}$ & $\begin{array}{l}\text { PCR } \\
\text { efficiency }(\%)^{\mathrm{b}}\end{array}$ \\
\hline $\begin{array}{l}\text { Leishmania } \alpha \text {-tubulin } \\
\text { Leishmania CPB }\end{array}$ & 85.2 & 78 \\
Leishmania CPC & 85.2 & 92 \\
Murine $\beta$-actin [CBA] & 78.5 & 82 \\
Murine MHC class I [CBA] & 77.9 & 101 \\
Murine MHC class II $(\alpha$-chain) [CBA] & 83.0 & 58 \\
Murine $\beta$-actin [BALB/c] & 79.7 & 86 \\
Murine MHC class I [BALB/c] & 77.9 & 112 \\
Murine MHC class II $(\alpha$-chain) [BALB/c] & 83.4 & 83 \\
\hline
\end{tabular}

${ }^{\mathrm{a}}$ Melting temperature represents the temperature where $50 \%$ of a PCR product is dissociated (single stranded).

b PCR efficiency (\%) represents the percentage of product copies present at the beginning a PCR cycle that is doubled by the end of the cycle, as measured by fluorescence intensity. indicated that these factors are also suppressed during $L$. (L.) amazonensis infection when compared to $L$. (L.) major infection data. More interestingly, the study of the expression of cytokines and chemokines receptors in CD4+ Tcells from this system suggests that there is a selective impairment of the expression of these receptors in $L$. (L.) amazonensis-infected mice rather than a generalized one.

Other reports indicate alterations in gene expression profiles of hosts infected with different Leishmania species. It was shown previously, using RPA and quantitative PCR, that in the lesion site of C57BL/10ScSn mice infected with $L(L$.) major, up-regulation of MIP1 and MCP-1 genes expression can be detected early in the infection and, in a later phase, RANTES and IFN- $\gamma$-induced protein (IP)-10 genes also become strongly up-regulated [18]. In that same study, it was shown that in the lesion-draining lymph node the gene expression profile is strikingly distinct from that of the lesion: MCP1 and IP-10 genes are strongly up-regulated but RANTES gene is

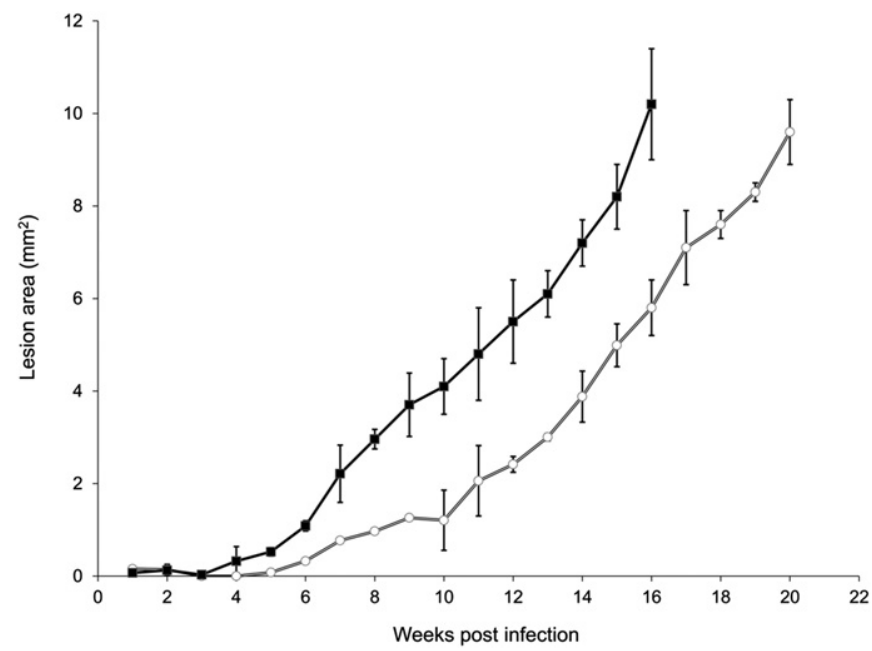

Fig. 2. Development of lesions in BALB/c ( $\boldsymbol{\square})$ and $\mathrm{CBA}(O)$ mice infected by $L$. (L.) amazonensis. Animals were infected subcutaneously with $1 \times 10^{6}$ promastigotes at the posterior left hindpawn. Follow-up of lesion development was carried out weekly by measuring the hindpawn width and height with a pachymeter. For each murine strain, three animals were chosen randomly each week for the measurements. Results represent the mean of three mice \pm standard deviation (SD) 

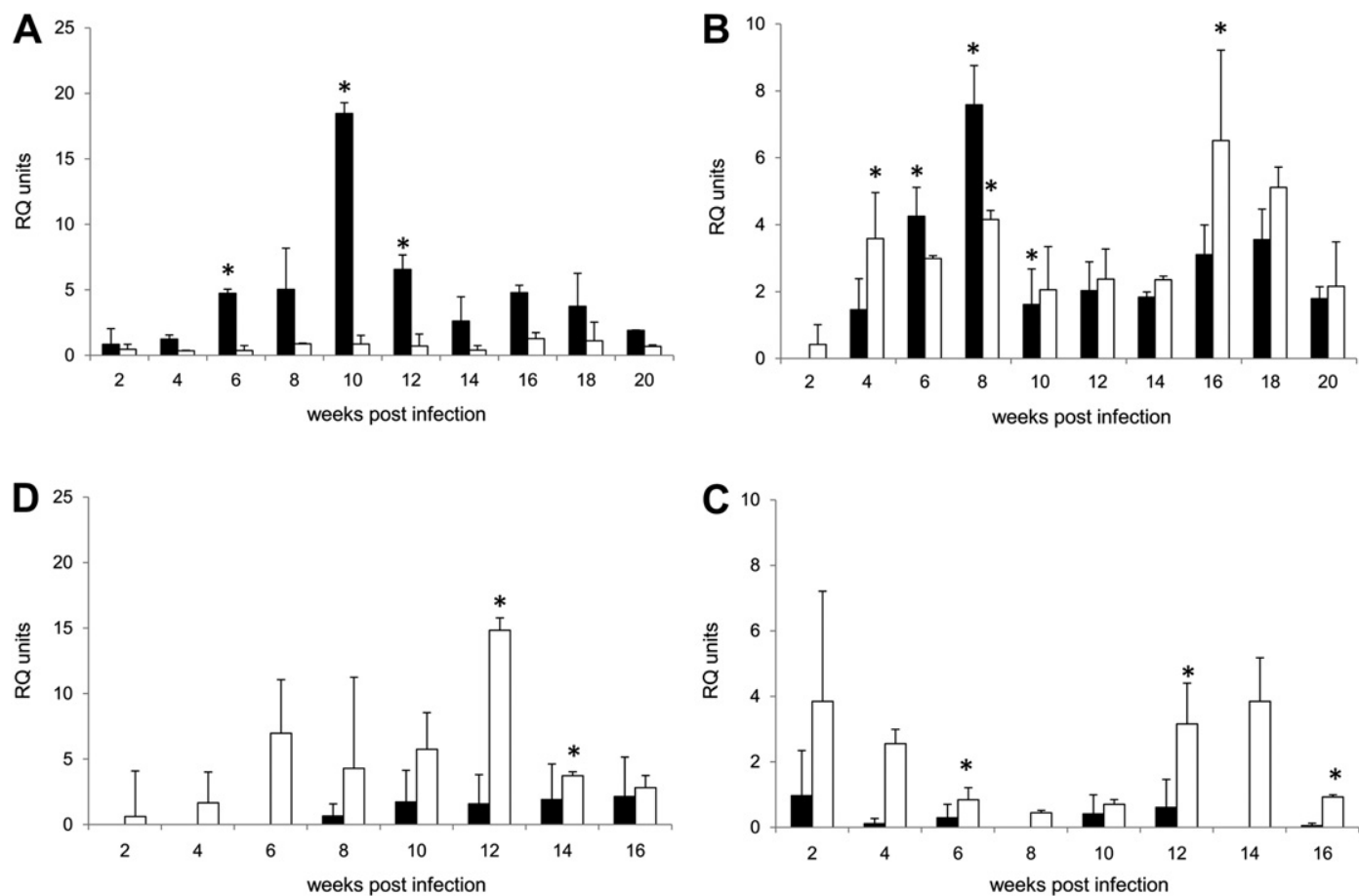

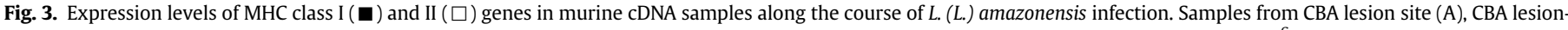

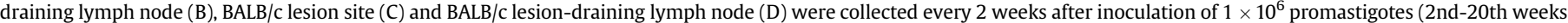

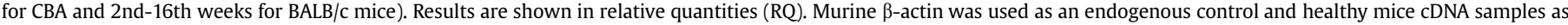

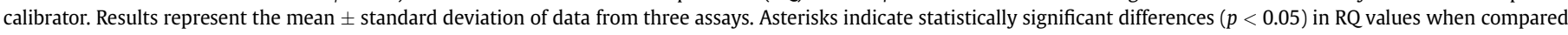
to data from the previous time point

down-regulated early in the infection but, later, IP-10 and RANTES return to constitutive levels, while MCP-1 remains up-regulated.

Infection of BALB/c macrophages with $L$. (L.) major, as well as with Leishmania (Leishmania) donovani, in vitro was shown, by microarray and quantitative PCR, to repress expression of chemokine receptor (CCR)-5 and histocompatibility complex class II genes in these cells [19].

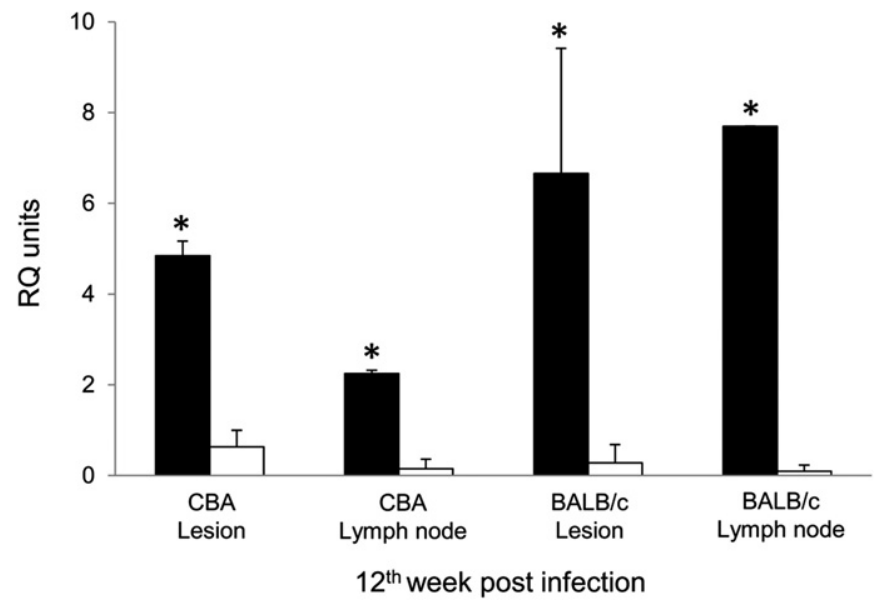

Fig. 4. Expression levels of Leishmania CPB $(\boldsymbol{\square})$ and $\mathrm{CPC}(\square)$ genes in murine cDNA samples from $L$. (L.) amazonensis-infected animals at a representative time point postinfection (12th week). Samples from CBA lesion site, CBA lesion-draining lymph node, $\mathrm{BALB} / \mathrm{c}$ lesion site and BALB/c lesion-draining lymph node were assayed. Results are shown in relative quantities (RQ). Leishmania $\alpha$-tubulin was used as an endogenous control and promastigotes cDNA samples as calibrator. Results represent the mean \pm standard deviation of data from three assays. Asterisks indicate statistically significant differences $(p<0.05)$ in CPB RQ values when compared to data from CPC at the same time point.
These reports underline the relevant effects that Leishmania parasite causes on host's cells gene expression patterns and indicate it as an important field of study to understand the details regarding parasite-host interactions.

The effects of in vitro infection by Leishmania (Leishmania) chagasi in the gene expression profile of BALB/C macrophages was also assessed using microarray, quantitative PCR and RPA and indicated a series of differences from non-infected macrophages: the levels of some proinflammatory chemokines mRNA (like MIP- $1 \alpha$, MIP- $1 \beta$ and MCP-1) were slightly decreased early in the infection. Also, the expression of CCR3 and CCR5 was down-regulated. The overall pattern pointed toward an increase in the expression levels of genes related to alternative activation of macrophages and a downregulation for genes of the classic activation pathway [20].

Our objective in this study was to combine the many advantages of a sensitive tool, as real-time PCR analysis, with a reliable model of Leishmania infection, as the murine model, to establish a flexible methodology that is able to investigate the complex network that link host and parasites during infection.

For this study, we selected genes of factors that play important roles in the T cell responses in mice infected with $L$. (L.) amazonensis. The T cell response is directly linked to host resistance or susceptibility to Leishmania infection, as the balance of $\mathrm{T}$ helper cell responses is pivotal in mice infected with parasites from the $L$. (L.) mexicana complex. The predominance of a Th type 2 response is usually associated with exacerbation of the disease, while a predominant Th type 1 response is a good prognosis for disease control $^{5}$. Additionally, the activation of a cytotoxic $\mathrm{T}$ cell response and CD8 + cells effector mechanism have been shown to be necessary for an efficient immune response against these parasites [6,21].

Thus, we chose to investigate the gene expression patterns of MHC molecules in the murine host, given that they perform key roles in the definition of $\mathrm{T}$ cell responses. Concomitantly, we 
analyzed Leishmania CPs genes expression, as many reports have shown that these enzymes can alter Th responses by an array of mechanisms $[8,11]$. Considering that part of our study is based on the expression of genes from the host immune system, we decided to focus on central immune sites of murine experimental Leishmania infection, including the lesion and its draining lymph node.

We selected two strains of mice with distinct levels of susceptibility to Leishmania infection to perform our assays. We considered that infection-related gene expression patterns could differ due to genotypic variations and could relate to their ability to deal with the parasites. The data obtained for the expression of MHC genes support this hypothesis, and we observed that MHC class I genes tend to have higher RQ values in CBA mice, whereas MHC class II RQ levels are predominant in BALB/c mice. This is a very interesting result as it shows that the more susceptible strain (BALB/c) has a higher expression of an MHC class that can lead to an ineffective response to infection (if promoting a Th2 response), while the more resistant strain (CBA) has higher expression of an MHC class related to control of infection (by promoting a Tc response).

Therefore, the enhanced expression of MHC class II genes in $\mathrm{BALB} / \mathrm{c}$ mice, both at the site of the lesion and in the draining lymph nodes, may be related to a reported role of CD4+ T cells in infection progression. This MHC class is classically related to induce CD4+ T cells activation and the absence of CD4+ T cells have been shown to be related of host control of the infection [22].

CBA mice presented a predominance of MHC class I gene expression at the site of the lesion throughout the course of infection, but such pattern was not observed in the draining lymph node. In this site, the predominantly expressed MHC class showed a tendency to invert from class I to class II starting at the 16th week post-infection. Perhaps the differences observed in the expression of genes that control T cell responses between BALB/c and CBA mice may account for their differential susceptibilities to infection.

As for the CP genes expression patterns in the parasite, a remarkable distinction in the two murine strains tested could be observed. When infecting BALB/c mice, parasites tend to express higher levels of CPB genes than those infecting CBA mice. Previous reports indicate that $\mathrm{CPB}$ enzymes act as modulators of the Th response [8]. Therefore, these enzymes may be important for the parasite control over the host Th response in the BALB/c mice, while, in CBA mice, they may have a lower importance due to a possibly distinct lymphocyte response (Tc response).

Cysteine-proteinase $C$ gene expression did not show any distinctive pattern between the strains of mice tested and its role in murine Leishmania infection remains unclear, even though this enzyme has been previously reported as playing a role in human leishmaniasis, by activating latent human transforming growth factor $\beta$ [23].

Based on our results, it seems likely that the genotype of the mouse strain and the levels of parasite CPB genes expression are important for defining the development of the experimental murine infection with $L$. (L.) amazonensis. It is possible that these are congruent factors, which influence the organization of $\mathrm{T}$ cell responses in $L$. (L.) amazonensis-infected mice, thus enhancing resistance or susceptibility.

The data gathered in our assays led us to consider the massive potential of gene expression assays in helping to realize the fine interactions that occur between host and parasite in the murine model of Leishmania infection.

The analysis of gene expression patterns in both host and parasites during infection and the comparison of data gathered in distinct models can help to address specific questions regarding host-parasite interactions which, eventually, can be combined to form a comprehensive panel of such interactions.
Furthermore, we propose that infection studies that apply a combination of gene expression methodologies with analyses of protein levels would be of vital importance, as such approach may lead to a profound understanding of the regulation and responses that occur in the murine model of Leishmania infection and, thus, lead to the development of very specific and efficient novel vaccines and chemotherapies.

\section{Conflict(s) of interest}

The authors or their institution do not have any relationships that may influence or bias the results and data presented in this manuscript.

\section{Acknowledgments}

This project was partially supported by PAPES (Fiocruz/CNPq) and FAPERJ. Dr Carlos R. Alves and Dr Constança Britto are fellows of the CNPq Institution. Dr Bernardo A. S. Pereira is a post-doctorate student supported by CAPES/Faperj. The authors would like to thank the PDTIS/Genomic-DNA Sequencing and Real-Time PCR technological platforms of Fundação Oswaldo Cruz for support in the assays.

\section{References}

[1] Alvar J, Aparicio P, Aseffa A, Den Boer M, Cañavate C, Dedet JP, et al. The relationship between leishmaniasis and AIDS: the second 10 years. Clin Microbiol Rev 2008;21:334-59.

[2] Lindoso JAL, Lindoso AABP. Neglected tropical diseases in Brazil. Rev Inst Med Trop S Paulo 2009;51:247-53.

[3] Marzochi MCA, Marzochi KBF. Tegumentary and visceral leishmaniases in Brazil: emerging anthropozoonosis and possibilities for their control. Cad Saúde Pública 1994;10:359-75.

[4] Reithinger R, Dujardin JC, Louzir H, Pirmez C, Alexander B, Brooker S. Cutaneous leishmaniasis. Lancet Infect Dis 2007;7:581-96.

[5] Alexander J, Bryson K. T helper(h)1/Th2 and Leishmania: paradox rather than paradigm. Immunol Lett 2005;99:17-23.

[6] Ruiz JH, Becker I. CD8 cytotoxic T cells in cutaneous leishmaniasis. Parasite Immunol 2007;29:671-8.

[7] Pereira BAS, Alves CR. Immunological characteristics of experimental murine infection with Leishmania (Leishmania) amazonensis. Vet Parasitol 2008;158: 239-55.

[8] Mottram JC, Coombs GH, Alexander J. Cysteine peptidases as virulence factors of. Leishmania Curr Opin Microbiol 2004;7:375-81.

[9] Alexander J, Coombs GH, Mottram JC. Leishmania mexicana cysteine proteinase-deficient mutants have attenuated virulence for mice and potentiate a Th1 response. J Immunol 1998;161:6794-801.

[10] Cameron P, McGachy A, Anderson M, Paul A, Coombs GH, Mottram JC, et al. Inhibition of lipopolysaccharide-induced macrophage IL-12 production by Leishmania mexicana amastigotes: the role of cysteine peptidases and the NFkappaB signaling pathway. J Immunol 2004;173:3297-304.

[11] Alves CR, Benévolo-De-Andrade TC, Alves JL, Pirmez C. Th1 and Th2 immunological profile induced by cysteine proteinase in murine leishmaniasis. Parasite Immunol 2004;26:127-35.

[12] Carter KC, Hutchison S, Henriquez FL, Légaré D, Ouellette M, Roberts CW, et al. Resistance of Leishmania donovani to sodium stibogluconate is related to the expression of host and parasite $\gamma$-glutamylcysteine synthetase. Antimicrob Agents Chemother 2006;50:88-95.

[13] Overbergh L, Valckx D, Waer M, Mathieu C. Quantification of murine cytokine mRNAs using real time quantitative reverse transcriptase PCR. Cytokines 1999; 11:305-12.

[14] Neal RA, Hale C. A comparative study of susceptibility of inbred and outbred mouse strains compared with hamsters to infection with new world cutaneous leishmaniases. Parasitology 1983;87:7-13.

[15] Calabrese KS, DaCosta SC. Enhancement of Leishmania amazonensis infection in BCG non-responder mice by BCGantigen specific vaccine. Mem Inst Oswaldo Cruz 1992;87:49-56.

[16] Osorio y Fortéa J, de La Llave E, Regnault B, Coppée JY, Milon G, Lang T, et al. Transcriptional signatures of BALB/C mouse macrophages housing multiplying Leishmania amazonensis amastigotes. BMC Genomics 2009;10:119.

[17] Ji J, Sun J, Soong L. Impaired expression of inflammatory cytokines and chemokines at early stages of infection with Leishmania amazonensis. Infect Immun 2003;71:4278-88.

[18] Antoniazi S, Price HP, Kropf P, Freudenberg MA, Galanos C, Smith DF, et al. Chemokine gene expression in toll-like receptor-competent and -deficient mice infected with Leishmania major. Infect Immun 2004;72:5168-74. 
[19] Gregory DJ, Sladek R, Olivier M, Matlashewski G. Comparison of the effects of Leishmania major or Leishmania donovani infection on macrophage gene expression. Infect Immun 2008;76:1186-92.

[20] Rodriguez NE, Chang HK, Wilson ME. Novel program of macrophage gene expression induced by phagocytosis of Leishmania chagasi. Infect Immun 2004;72:2111-22.

[21] Colmenares M, Kima PE, Samoff E, Soong L, McMahon-Pratt D. Perforin and gamma interferon are critical CD8+ T-cell-mediated responses in vaccine- induced immunity against Leishmania amazonensis infection. Infect Immun 2003;71:3172-82.

[22] Silva EM, Bertho AL, Mendonça SC. Effect of in vivo depletion of CD4+ T cells on experimental infection of susceptible BALB/c mice with Leishmania amazonensis. Acta Trop 1994;56:111-20.

[23] Somanna A, Mundodi V, Gedamu L. Functional analysis of cathepsin B-like cysteine proteases from Leishmania donovani complex. evidence for the activation of latent transforming growth factor beta. J Biol Chem 2002;277:25305-12. 